\title{
EFFECTS OF PROBIOTIC SACCHAROMYCES BOULARDII AND CO- TRIMOXAZOLE ON SOME HAEMATOLOGICAL PARAMETERS IN ADULT WISTAR RATS
}

\author{
${ }^{* 1}$ Obazelu, P. A., ${ }^{2}$ Aruomaren, A. I. \& ${ }^{3}$ Nwangwu, C. C. \\ *I\&2 Department of Medical Laboratory Science, School of Basic Medical Sciences, University of Benin, Benin City, Nigeria \\ *Corresponding Author's E-mail: progress.obazelu@ uniben.edu Phone: +2348056733255
}

\begin{abstract}

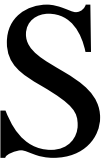

accharomyces boulardii is a probiotic yeast used as a nutritional supplement. Co-trimoxazole, is a broadspectrum antimicrobial agent used in the prophylaxis and treatment of infections. The goal of this study was to evaluate the individual and interactive effects of probiotic Saccharomyces boulardii and co-trimoxazole on some haematological parameters in albino rats. Thirty (30) albino Wistar rats weighing 150-200g were divided into five groups; Basal, A, B, C, and D, with six animals in each group. Group A (control) was given a normal rat pellet (standardized feed) and clean water (pH 6.5- 8.5). Group B was administered $5.5 \mathrm{mg} / \mathrm{kg}$ body weight of the commercial probiotics (Saccharomyces boulardii). Group C was administered $4.4 \mathrm{mg} / \mathrm{kg}$ body weight of co-trimoxazole. Group D was administered $5.5 \mathrm{mg} / \mathrm{kg}$ body weight of the commercial probiotics and $4.4 \mathrm{mg} / \mathrm{kg}$ body weight of co-trimoxazole. All administrations were done using a gavage tube for 15 days. Blood samples were collected for analysis on days 0 , 5 and 15. The results showed that Saccharomyces boulardii caused a significant increase $(\mathrm{P}<0.05)$ in total white blood cell count and packed cell volume of the treated groups at day 5. On day 15, the total white blood cell count (10.67 \pm 0.66$)$, packed cell volume $(43.23 \pm 0.47)$, platelet count $(932 \pm 38.89)$ and mean platelet volume $(8.53 \pm 0.38)$ showed a significant increase $(\mathrm{P}<0.05)$ in the probiotic group. The co-trimoxazole group showed a significant reduction $(\mathrm{P}<0.05)$ in the packed cell volume and total white blood cell count. This study shows that Saccharomyces boulardii has a positive effect on the haematological profile of the test animals.
\end{abstract}

Keywords: Saccharomyces boulardii, co-trimoxazole, packed cell volume, total white blood cell count, platelet count, mean platelet volume

COPYRIGHT: The Author(s) completely retain the copyright of this published article.

OPEN ACCESS: The Author(s) approves that this article remains permanently online in the open access (OA) model 


\section{INTRODUCTION}

According to the Food and Agriculture Organization of the United Nations and the World Health Organization, probiotics are living microorganisms that imparts health value to the host when given in ample quantities (FAO/WHO,2002).

Disease prevention and treatment as well as enhancing digestion and absorption are some of the beneficial effects it gives to its host (Dahiya et al., 2012). Although this advantageous effect was thought to stem from an upgrade of the intestinal microbial balance, there is now considerable proof that probiotics can also provide value by modulating immune functions (Gogineni et al.,2013). Saccharomyces boulardii is a selected strain of nonpathogenic yeast, which is designed as a probiotic for humans (Tiago et al., 2012). The effectiveness and safety of Saccharomyces boulardii for diverse diseases like irritable bowel syndrome, diarrhoea and Crohn's disease have been illustrated by several clinical trials (Szajewska and Kolodziej, 2015). Saccharomyces boulardii was discovered in 1923 by a French microbiologist known Henri Boulard (Niamah, 2017). Saccharomyces boulardii was isolated from Lychees fruit (Litchi chinensis) and Mangosteen fruit (Garcinia mangostana) grown in warm tropics in Indochina. It is a eukaryotic, single-cell yeast organism with an optimal growth temperature of 37 degrees Celcius (Niamah, 2017). Saccharomyces boulardii is a non-pathogenic probiotic yeast which is can be used in preventing and/or treating intestinal disorders, comprising antibiotic-associated diarrhoea, acute diarrhoea in adults and children which might be caused by several pathogens. Several studies have stated that Saccharomyces boulardii is a safe and well-tolerated treatment when administered orally (Samonis et al.,2011). Also, the metabolic extract of Saccharomyces boulardii was found to inhibit

26 species of food related bacteria (Niamah, 2017). It is can also survive gastric acidity and does not change or unpleasantly affect the normal flora in the bowel. Further, Saccharomyces boulardii is resistant to antibiotics naturally and are not affected by sulfamide (Tomicic et al., 2016).

Co-trimoxazole is a drug, it consists of trimethoprim and sulfamethoxazole. Trimethoprim (2,4-diamino-5(3,4,5-tri methoxybenzyl pyrimidine), and exhibits antibacterial and antimalarial activity (Manyando et al., 2013). Cotrimoxazole has been used for over half a century. It is used globally for the treatment of bacterial infections such as pneumonia and tuberculosis. It is also commonly used as prophylaxis against secondary bacterial infections among HIV-infected tuberculosis patients (Fadeyi et al., 2015). It is effective in treating and preventing malaria (Fadeyi et al., 2015, Manyando et al., 2013). Co-trimoxazole is commonly sold over the counter as the drug known as septrin and has been used most times as an unprescribed drug for the treatment of cough and upper respiratory tract infections ( Ekwochi et al., 2014). The blood changes connected with the administration of co-trimoxazole (septrin) in humans were evaluated by (Onyebuagu et al., 2014). The results showed that blood cells were significantly decreased after septrin administration and alterations in blood parameters can occur as a result of administration of septrin (Onyebuagu et al., 2014).

Saccharomyces boulardii is commonly used in the preventing and/or treatment of intestinal disorders, including in individuals taking the antibiotic co-trimoxazole, such as HIV infected individuals. Not much is known about its impact on blood parameters. Also, co-trimoxazole is one of the most widely consumed antibiotics due to its availability and broad clinical spectrum use. The aim of this study was to evaluate the individual and interactive effects of probiotic Saccharomyces boulardii and co-trimoxazole on some haematological parameters. 


\section{METHODOLOGY EXPERIMENTAL DESIGN}

Thirty (30) adult Wistar rats, of both sexes, weighing 150-200g were divided into five groups, with six rats in each group. The groups were the Basal group (day 0), Group A (control), Group B (probiotics test group), Group C (cotrimoxazole test group) and Group D (probiotics and co-trimoxazole test group). All administrations were done using an orogastric tube for 15 days.

The basal group served as the baseline values for the experiment. Animals in this group were stabilized along with other animals, but were sacrificed before treatment commenced. Animals in the control group (Group A), received only standardized feed and clean water throughout the period of the experiment. Neither co-trimoxazole nor Saccharomyces boulardii was given to this group.

\section{DOSAGE}

Flora Norm (Saccharomyces boulardii) at $5.5 \mathrm{mg} / \mathrm{kg}$ body weight was given to the Saccharomyces boulardii test group for fifteen days (Group B). For fifteen days, the co-trimoxazole test group received $4.4 \mathrm{mg} / \mathrm{kg}$ body weight of septrin (co-trimoxazole) (Group C). $5.5 \mathrm{mg} / \mathrm{kg}$ body weight of Flora Norm (Saccharomyces boulardii) and $4.4 \mathrm{mg} / \mathrm{kg}$ body weight of septrin (co-trimoxazole) were given to the Saccharomyces boulardiiand co-trimoxazole group for fifteen days (Group D).

\section{DETERMINATION OF HAEMATOLOGICAL PARAMETERS}

Blood samples were obtained by heart puncture on days 0,5, and 15 and placed in EDTA containers for haematological tests. The automated analyzer, ERMA INC Full Automatic Blood Cell Counter, model PCE-210N, was used to perform the Full Blood Count test on all of the samples

\section{STATISTICAL ANALYSIS}

The SPSS version 20.0 was used to analyze the data. The data was presented in the form of a mean and standard deviation. The one-way analysis of variance was used to compare the means of the four groups (ANOVA). Statistical significance was defined as a p-value of less than 0.05 .

\section{RESULTS}

Table 1 shows the Mean \pm standard error of the mean of full blood count results on the effects of Saccharomyces boulardii and co-trimoxazole in adult Wistar rats at Day 5. When compared to the basal group (6.95 \pm 0.26$)$ and Group A (7.1 \pm 0.25$)$, Group B's total white blood cell count (TWBC) increased significantly ( $\mathrm{P}<0.001)$. When compared to Group B (10.47 \pm 0.58$)$, Group C (7.23 \pm 0.03$)$ demonstrated a statistically significant decrease. The total white blood cell count (TWBC) of Group D (9.2 \pm 0.69$)$ increased significantly when compared to the basal group (6.95 \pm 0.26$)$ and Group A (7.1 \pm 0.25$)$, but decreased significantly when compared to Group B. In all of the groups, the lymphocyte (percent), monocyte (percent), and granulocyte (percent) exhibited no statistical significance. 
The red blood cell count and haemoglobin concentration (HB) showed no statistical significance in all the groups. The results revealed a statistically significant rise in the packed cell volume (PCV) of Group B (43.23 \pm 0.47$)$ when compared with the basal group (40.27 \pm 0.49$)$, and a significant decrease in Group C (40.9 \pm 0.25$)$ when compared with Group B (43.23 \pm 0.47 ). The platelet count, mean platelet volume (MPV) and platelet distribution width (PDW) was not significant in all the groups. The mean cell volume (MCV), mean corpuscular haemoglobin $(\mathrm{MCH})$ and mean corpuscular haemoglobin concentration (MCHC) were not statistically significant in all the groups at Day 5 .

Table 1: Full blood count results of all groups at Day 5.

\begin{tabular}{|c|c|c|c|c|c|c|}
\hline PARAMETER & $\begin{array}{l}\text { BASAL } \\
\text { GROUP } \\
\text { (DAY 0) }\end{array}$ & $\begin{array}{l}\text { GROUP A } \\
\text { (Control) }\end{array}$ & $\begin{array}{l}\text { GROUP B } \\
\text { (Saccharomyces } \\
\text { boulardii only) }\end{array}$ & $\begin{array}{l}\text { GROUP C } \\
\text { (Co- } \\
\text { trimoxazole } \\
\text { only) }\end{array}$ & $\begin{array}{l}\text { GROUP D } \\
\text { (Saccharomyces } \\
\text { boulardii }+ \text { Co- } \\
\text { trimoxazole) }\end{array}$ & P VALUE \\
\hline TWBC $\left(\mathrm{X} 10^{9} / 1\right)$ & $6.95 \pm 0.26$ & $7.1 \pm 0.25$ & $10.47 \pm 0.58^{\mathrm{ab}}$ & $7.23 \pm 0.03^{c}$ & $9.2 \pm 0.69^{\mathrm{abc}}$ & $<0.001$ \\
\hline Lymphocytes (\%) & $84.52 \pm 1.53$ & $84.03 \pm 1.02$ & $86.87 \pm 1.18$ & $88.13 \pm 0.98$ & $89 \pm 1.3$ & 0.131 \\
\hline Monocytes (\%) & $8.8 \pm 0.88$ & $9.8 \pm 2.15$ & $8.17 \pm 0.75$ & $7.8 \pm 0.51$ & $7 \pm 0.8$ & 0.556 \\
\hline Granulocytes (\%) & $4.5 \pm 0.41$ & $4.5 \pm 0.66$ & $5.3 \pm 0.67$ & $4.23 \pm 0.43$ & $4 \pm 0.5$ & 0.591 \\
\hline $\mathrm{RBC}\left(\times 10^{9} \Lambda\right)$ & $7.05 \pm 0.42$ & $6.78 \pm 0.13$ & $7.58 \pm 0.08$ & $6.76 \pm 0.15$ & $7.15 \pm 0.20$ & 0.572 \\
\hline $\mathrm{HB}(\mathrm{g} / \mathrm{dl})$ & $12.93 \pm 0.40$ & $13.2 \pm 0.61$ & $14.53 \pm 0.23$ & $13.6 \pm 0.06$ & $14.07 \pm 0.23$ & 0.079 \\
\hline $\operatorname{PCV}(1 / 1)$ & $40.27 \pm 0.49$ & $40.93 \pm 0.32$ & $43.23 \pm 0.47^{\mathrm{a}}$ & $40.9 \pm 0.25^{\mathrm{c}}$ & $41.9 \pm 0.36$ & 0.006 \\
\hline Platelets $\left(\times 10^{9} / 1\right)$ & $553.3 \pm 44.68$ & $514 \pm 35.02$ & $670 \pm 50.9$ & $567 \pm 26.89$ & $637.7 \pm 48.22$ & 0.216 \\
\hline MPV (fl) & $7.13 \pm 0.37$ & $7.43 \pm 0.57$ & $7.233 \pm 0.19$ & $7.17 \pm 0.09$ & $7.13 \pm 0.09$ & 0.978 \\
\hline PDW $(\%)$ & $11.07 \pm 1.5$ & $10.23 \pm 1.28$ & $8.97 \pm 0.64$ & $9.2 \pm 0.29$ & $8.97 \pm 0.39$ & 0.666 \\
\hline $\operatorname{MCV}(\mathrm{fl})$ & $62.43 \pm 1.35$ & $60.43 \pm 1.43$ & $61.53 \pm 2.62$ & $63.27 \pm 2.33$ & $58.73 \pm 1.27$ & 0.499 \\
\hline $\mathrm{MCH}(\mathrm{pg})$ & $19.43 \pm 0.19$ & $19.73 \pm 0.28$ & $19.37 \pm 0.26$ & $19.5 \pm 0.35$ & $19.8 \pm 0.45$ & 0.806 \\
\hline $\operatorname{MCHC}(\mathrm{g} / \mathrm{dl})$ & $31.73 \pm 0.87$ & $32.2 \pm 1.62$ & $33.33 \pm 0.41$ & $32.77 \pm 0.34$ & $33.77 \pm 0.07$ & 0.587 \\
\hline
\end{tabular}

Table 2 shows the Mean \pm standard error of the mean of full blood count results on the effects of Saccharomyces boulardii and co-trimoxazole in adult Wistar rats at Day 15. The total white blood cell count (TWBC) of Group B (10.67 \pm 0.66$)$ was significantly increased compared to the basal group (6.95 \pm 0.26$)$ and Group A (7.5 \pm 0.15$)$. Group C $(6.03 \pm 0.29)$ showed a significant reduction when compared with Group B $(10.67 \pm 0.66)$. The results revealed a significant decrease in the monocyte (percent) of Group B (4.3 \pm 1.50$)$ compared to the basal group (8.8 \pm 0.88$)$. However, the monocyte (percent) of Group C $(10.73 \pm 1.60)$ increased significantly compared to Group B (4.3 \pm 1.50$)$. The lymphocyte (percent) and granulocyte (percent) showed no statistical significance in all the groups.

The result revealed no statistical significance in the red blood cell count of all the groups. However, the haemoglobin concentration (HB) of Group B (14.93 \pm 0.44$)$ and Group D (14.93 \pm 0.44$)$ showed a significant increase compared to the Basal group (12.93 \pm 0.40 ). There was a significant rise in the packed cell volume (PCV) of Group B

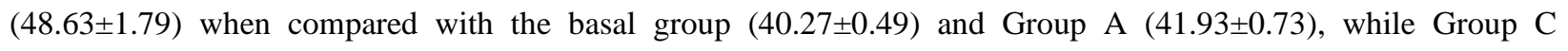


(38.47 \pm 1.08$)$ showed a significant decrease compared to Group B $(48.63 \pm 1.79)$. Also, the packed cell volume (PCV)

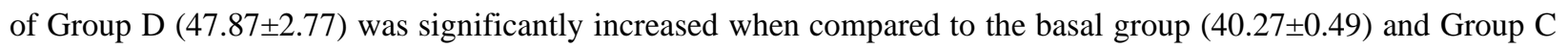

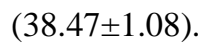

The platelet count of Group A $(864.3 \pm 19.1)$, Group B $(932 \pm 38.89)$ and Group D $(902.7 \pm 68.86)$ showed a

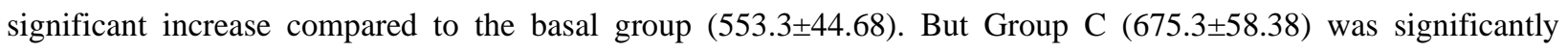
decreased compared to Group B $(932 \pm 38.89)$. The mean platelet volume (MPV) of Group B $(8.53 \pm 0.38)$ showed a significant increase compared to Group A $(6.27 \pm 0.37)$. However, the platelet distribution width (PDW) was not statistically significant in all the groups.

The red cell parameters which include the mean cell volume (MCV), mean corpuscular haemoglobin (MCH) and mean corpuscular haemoglobin concentration $(\mathrm{MCHC})$ were not statistically significant in all the groups at Day 15.

Table 2: Full blood count results of all groups at Day 15.

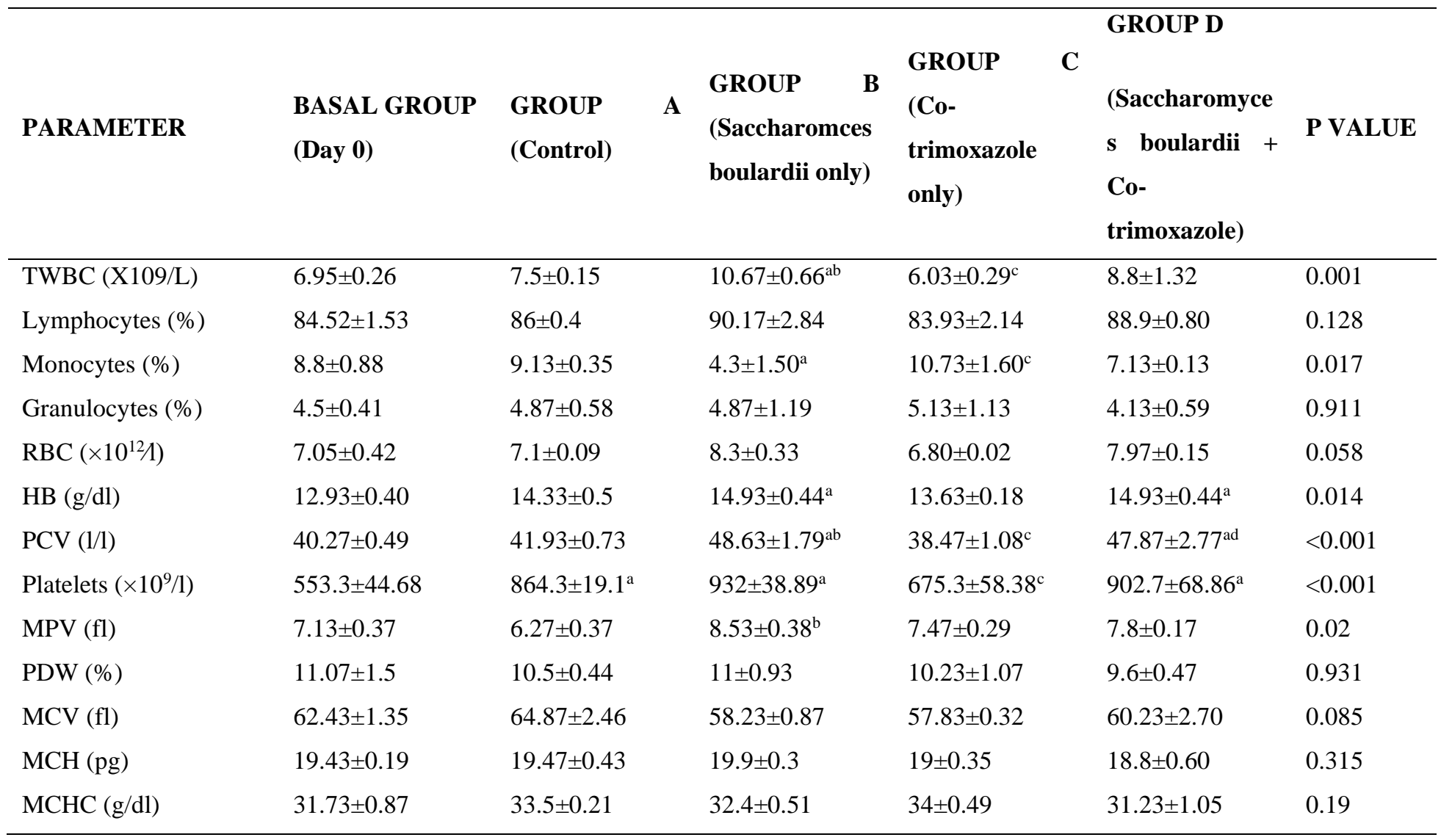




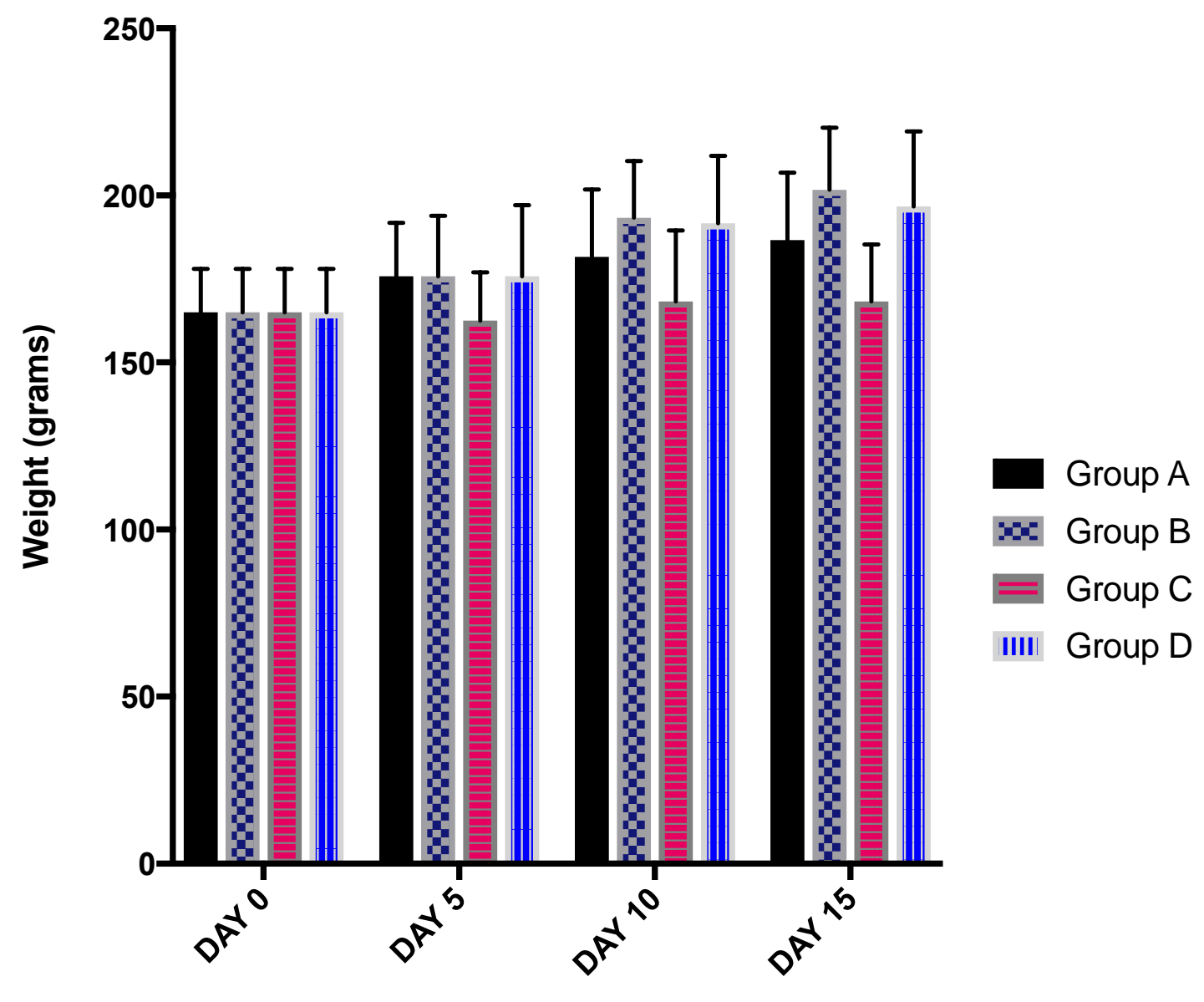

Figure 1: The body weights of Group A, B, C and D measured at Day 0, 5, 10 and 15. Group A and B showed a steady increase in weight gain.

Also, the weight gain of Group A was higher than all other groups on the different days. Group C showed a decrease in body weight from Day 0 to 5, showed a slight increase at Day 10 and a slight decrease from Day 10 to 15 . Also, it had the lowest body weight among all the groups on the different days. Group D showed a steady increase in weight gain but their weights were lower than that of Group B but higher than Group A and C in all the days.

\section{DISCUSSION}

This study was conducted to explore the effect of probiotic Saccharomyces boulardii and the antibiotic co-trimoxazole on some haematological parameters in adult Wistar rats. The findings of this study obtained on Day 5 (Table 1) demonstrated that the animals fed with the probiotic Saccharomyces boulardii recorded a significant increase $(\mathrm{P}<0.05)$ in total white blood cell count and packed cell volume when compared with the other groups. These findings shows that probiotics have immunostimulatory effects. This is in agreement with Ezema and Eze (2012). The group which 
was administered both the probiotic saccharomyces boulardii and the antibiotic co-trimoxazole showed significantly higher total white blood cell count compared to Group $\mathrm{C}$ which received only co-trimoxazole, indicating cotrimaxazole had no antagonistic effect on the probiotic supplement (Tomicic et al., 2016). On day 15, the Saccharomyces boulardii test group showed a significant increase in total white blood cell count, haemoglobin concentration, packed cell volume and platelet count. This suggests that this probiotic may have caused an increase in bone marrow activity. Similar to the findings of this study, it was observed that probiotics did not show damaging changes on blood haematological indices and it could better health conditions by increasing haemoglobin concentration, packed cell volume and red cell count (Abudahos et al., 2016).

The reduction in body weight which was seen in the co-trimoxazole group shows that co-trimoxazole might have enhanced satiation signals secreted by the gut. Glucagon-like peptide-1 (GLP-1) is a hormone formed in the Lcell of the gastrointestinal tract in reaction to food intake. It is also produced in the nucleus tractus solitarius cell bodies of the brain stem (Alhadeff et al., 2012). This enzyme diminishes appetite by acting on the vagal afferents that reach the nucleus tractus solitarius. Elevated levels of GLP-1 reduce gastric motility and gastric clearing and also reduces carbohydrate absorption.

\section{CONCLUSION}

This study shows that the probiotic Saccharomyces boulardii has a positive effect on the haematological profile of the test animals. Co-trimoxazole when administered alone to the test animals caused a decrease in the total white blood cell count and packed cell volume. Also, the antibiotic co-trimoxazole had no antagonistic effect with Saccharomyces boulardii.

\section{ACKNOWLEDGEMENTS}

All thanks to God Almighty for his love, grace, strength and divine provision. My sincere appreciation goes to my Miss Chioma Nwangwu and Mr A. I Aruomaren for their contributions towards the completion of this work. We will like to appreciate the Department of Medical Laboratory Science, University of Benin for giving us the space and opportunity. 


\section{REFERENCES}

Abudabos, A.M., Murshed, M.A., Qaid, M.M. and Abdelrahman, G.A. (2016). Effect of probiotics on serum biochemical and blood constituents in chicken challenged with Salmonella enterica Subspecies Typhimurium. Tropical Journal of Pharmaceutical Research. 15 (3): 461-467. doi: 10.4314/tjpr. v15i3.5.

Alhadeff, A., Rupprecht, L. and Hayes, M. (2012). GLP-1 neurons in the nucleus of the solitary tract project directly to the ventral tegmental area and nucleus acumens to control for food intake. Endocrinology. 153(2):64758. doi: 10.1210/en.2011-1443.

Dahiya, T., Sihag, R.C and Gahlawat, S.K. (2012). Effect of Probiotics on the Haematological Parameters of Indian Magur (Clarius batrachus L.). Journal of Fisheries and Aquatic Science.7(4):279-290. doi:10.3923/jfas.2012.279.290.

Ekwochi, U., Chinawa, J.M., Osuorah, C.D.I., Odetunde, O.I., Obu, H.A. and Agwu, S. (2014). The use of unprescribed antibiotics in management of upper respiratory tract infection in children in Enugu, South-East Nigeria. Journal of Tropical Pediatrics. 60(3): 249-252. doi:10.1093/tropej/fmt111.

Ezema, C and Eze, D.C. (2012). Determination of the effect of probiotics (Saccharomyces cerevisiae) on the growth performance and hematological parameters of rabbits. Comparative Clinical Pathology. 21(1): 73-76. doi:10.1007/s00580-010-1066-6.

Fadeyi, I., Lalani, M., Mailk, N., Van Wyk, A. and Kaur, H. (2015). Quality of the antibiotic's amoxicillin and Cotrimoxazole from Ghana, Nigeria, and the United Kingdom. The American Journal of Tropical Medicine and Hygiene. 92(6): 87-94. doi: 10.4269/ajtmh.14-0539.

FAO/WHO. (2002). Health and Nutritional properties of probiotics in food. Working Group Report on Drafting Guidelines for the Evaluation of Probiotics in Food London, Ontario, Canada. From: https://www.who.int/foodsafety/fs_management/en/probiotic_guidelines.pdf.

Gogineni, V.K., Morrow, L.E. and Malesker, M.A. (2013). Probiotics: Mechanisms of action and clinical applications. Journal of Probiotics \& Health. 1 (1): 101. doi: 10.4172/2329-8901.1000101.

Manyando, C., Njunju, E.M., D'Alessandro, U. and Van geertruyden, J.P. (2013). Safety and efficacy of cotrimoxazole for treatment and prevention of Plasmodium falciparum malaria: A systematic review. PloS ONE. 8 (2): e56916. doi: 10.1371/journal.pone.0056916.

Niamah, A.K. (2017). Physicochemical and microbial characteristics of yoghurt with added Saccharomyces boulardii. Current Research in Nutrition and Food Science. 5(3): 300- 307. doi:http://dx.doi.org/10.12944/CRNFSJ.5.3.15.

Onyebuagu, P.C., Kiridi, K. and Pughikumo, D.T. (2014). Effects of septrin administration on blood cells parameters in humans. International Journal of Basic, Applied and Innovative Research. 3(1): 14-18. From: www.arpjournals.com

Samonis, G., Falagas, M.E., Lionakis, S., Ntaoukakis, M., Kofteridis, D.P., Ntalas, I. and Maraki, S. (2011). Saccharomyces boulardii and Candida albicans experimental colonization of the murine gut. Medical Mycology. 49(4): 395-399. doi: 10.3109/13693786.2010.533203. 
Szajewska, H. and Kolodziej, M. (2015). Systemic review with meta-analysis: Saccharomyces boulardii in the prevention of antibiotic-associated diarrhoea. Alimentary Pharmacology \& Therapeutics. 42(7):793-801. doi: 10.1111/apt.13344.

Tiago, F.C.P., Martins, F.S., Souza, E.L.S., Pimenta, P.F.P., Araujo, H.R.C., Castro, I.M., Brandao, R.L. and Nicoli, J.R. (2012). Adhesion to the yeast cell surface as a mechanism for trapping pathogenic bacteria by Saccharomyces probiotics. Journal of Medical Microbiology. 61(9):1194-1207. doi:10.1099/jmm.0.0422830 .

Tomicic, Z.M., Colovic, R.R., Cabarkapa, I.S., Vukmirovic, M.E., Olivera, M.E. and Tomicic, M.R. (2016). Beneficial properties of probiotic yeast Saccharomyces boulardii. Food and Feed Research. 43(2): 103-110. From: https://en.engormix.com/feed-machinery/articles/beneficial-properties-probiotic-yeast-t45834.htm. 